Article

\title{
An Empirical Study on the Impact of Collaborative R\&D Networks on Enterprise Innovation Performance Based on the Mediating Effect of Technology Standard Setting
}

\author{
Hong Jiang ${ }^{1, *}$, Sipeng Gao ${ }^{1}$, Yang Song ${ }^{1}$, Kuang Sheng ${ }^{2}$ and Gehan A. J. Amaratunga ${ }^{3}$ \\ 1 School of Management, Jilin University, Changchun 130022, China; gossipgsp@163.com (S.G.); \\ songyang6779@163.com (Y.S.) \\ 2 College of Electrical Engineering, Zhejiang University, Hangzhou 310063, China; shengk@zju.edu.cn \\ 3 Department of Engineering, University of Cambridge, Cambridge CB3 0FA, UK; gaja1@cam.ac.uk \\ * Correspondence: jiang_hong@jlu.edu.cn
}

Received: 26 November 2019; Accepted: 12 December 2019; Published: 17 December 2019

\begin{abstract}
Against the background of economic globalization, high-technology enterprises need to focus on the characteristics of corporate collaboration R\&D networks and Standard-Setting. In this paper, theoretical research on corporate collaboration R\&D network characteristics, technology standard-setting capability, and technology innovation performance is carried out, and a theoretical model and hypotheses are constructed. We apply Structural Equation Modeling (SEM) to conduct an empirical analysis based on national data surveys of 12 industries. The conclusions are as follows: (1) Corporate collaboration R\&D networks and technology standard-setting capability have a positive and significant impact on technology innovation performance; (2) Technology's standard-setting capability has been identified to play a full intermediary role in the relationship between the breadth of connections and innovation efficiency. This paper provides a practical reference for enterprises to assess the value of collaborative R\&D networks and improve their technology standard-setting capability for enhanced economic efficiency.
\end{abstract}

Keywords: corporate collaboration R\&D network; technology innovation; technology standard-setting capability; technology innovation performance

\section{Introduction}

Standards promote the interconnection of countries and strengthen cooperation between countries worldwide. As market standard competition becomes increasingly fierce, enterprises are limited in terms of their scale, capital, and R\&D capabilities. Collaborative research and development among enterprises has emerged as a favorable model to overcome the limitations of individual enterprises.

Freeman found that with the formation of regional innovation networks, external resources such as market information have gradually played an increasingly important role in the successful innovation of enterprises [1]. Weiss and Cargill suggested that the R\&D Alliance and user groups have an important influence on the development of standards [2]. It can be seen that when companies face higher investment and high-risk needs such as technology research and development and standard formulation, they will choose to establish links with other innovation entities and develop a win-win collaborative research and development network. This can enable enterprises to obtain resources from different channels and enhance their technology level and competitive advantage.

At present, there are many empirical studies on the direct effects of corporate collaboration $R \& D$ network characteristics on technology innovation performance and the indirect effects of 
combining other variables. However, most of the research on technology standards is based on theoretical assumptions. In the 1980s, scholars such as Katz and Farrell introduced the theory of network externalities into the study of technology standards, which laid the foundation for the study of technology standardization [3-6]. Subsequent research by scholars such as Blind, Eisenmann, and Chakravarti explored the impact of technology standardization on corporate performance, industrial structure, and economic growth at the micro and macro levels [7-9]. In recent years, Fang, Blind, De Vries, and other scholars have conducted empirical research on the relationship between technology standardization and technology innovation [10-12]. In summary, there are currently few theoretical studies that put the characteristics of corporate collaboration R\&D network, technology standard-setting capability, and technology innovation performance within a unified framework, and there is a lack of quantitative empirical research among the three.

Furthermore, the enterprise collaboration R\&D network is of great significance and value for the development of technology standards and technology innovation performance in the following manner. The enterprise collaboration R\&D network breaks time and space boundaries, integrates the resources and information of enterprises and other entities, and develops technology achievements jointly. Stakeholders establish the industry's unified regulations with continuous negotiation and optimization, hence improving the technology standard-setting capability. Technology standard setting provides the specifications and guidance for product and technological process transformation, which benefits innovation output, the formation of corporate competitive advantage, and the improvement of technology innovation performance. In this paper, through detailed investigations of industries such as automobile, biological medicine, materials, etc., the relationships among enterprise collaboration R\&D network characteristics, technology standard-setting capability, and technology innovation performance are explored empirically at the micro-enterprise level based on social network theory and strategic alliance theory. This work aims to complement existing research from a different perspective.

\section{Theoretical Model Construction and Hypotheses}

\subsection{Theoretical Research Basis and Model Construction}

\subsubsection{Basic Theory}

\section{(1) Social network theory}

Social network theory originated from research in the fields of anthropology and psychology and matured in the 1970s. The earliest and most comprehensive social network concept was a relatively stable system composed of social relationships among individuals, which was proposed by Wellman [13]; with the continuous expansion of the practical application scope, social networks have gone beyond individual categories to economic organizations and social groups. In social networks, individuals and organizations, as the main body of the network, establish social contacts in social networks and are connected through direct or indirect cooperative relationships [14]. Information, funds, knowledge, and other forms of resources are transmitted through the network through connections [15]. The growth of individuals and organizations depends on resources, and multidimensional networks provide them with access to resources [16]. With the continuous deepening of research, social network theory has been widely applied in the fields of corporate organizational structure $[17,18]$, corporate strategic alliances [19,20], and industrial clusters [21,22]. The collaborative R\&D network, which is a collection of subject relations with the goal of innovation, is embedded in social networks and has the universal attributes of social networks.

\section{(2) Strategic alliance theory}

Strategic alliance theory evolved from strategic organization theory in the 1970s, and gradually formed in the late 1990s. The concept of the strategic alliance was first put forward by Hopland and Nagel [23]. In order to achieve the strategic goals of developing markets and using resources, two 
or more enterprises with common strategic interests and economic strength match each other [24,25]. Through contracts, they form a cooperation mode of complementary advantages, risk sharing and horizontal two-way or multi-directional flow of production factors [26]. Developed countries have already begun to use strategic alliance theory to guide corporate practical activities. In addition, cross-border cooperative innovation organizations formed by collaborative R\&D networks through sharing, dissemination, and integration of resources are an important form of strategic alliance.

\subsubsection{Definition of Concept}

\section{(1) Corporate collaboration R\&D network}

The innovation network is defined as a collaborative network formed by different innovation entities. The innovation entities jointly develop, produce, and sell new products, establish direct and indirect mutually beneficial relationships in technology, markets, and other aspects, and are linked through formal or informal contracts [27]. This article focuses on the technology cooperation and innovation among research innovation subjects, so the collaborative R\&D network is selected as one of the research variables in this article. The collaborative R\&D network has a virtualized enterprise agglomeration, and Doloreux and Shearmur proposed that a collaboration R\&D network is where individuals, companies, research institutes, intermediary organizations, governments, and other entities collaborate in R\&D activities, which include cooperative projects, theses, patents, etc. [28]. Wang defined the collaboration R\&D network as a network formed by different entities in the joint development of one or more technologies, and the entities have common interests, which will enhance the use of scientific and technological resources [29]. Based on the above definitions, we believe that the enterprise collaborative research and development network is one of the core innovation entities of many enterprises, and that it is used for participation in technology cooperation, patent cooperation, technology licensing, project cooperation, etc., through formal or informal relationships between enterprises or between other entities. In essence, we suggest that this network is an interconnected organizational system composed of technology research and development activities.

\section{(2) Technology standard-setting capability}

Blind defines standards as prescriptive documents such as rules, packaging, and symbols for products, processes, and production methods that are common in the industry after being approved by authoritative public agencies [7]. As the carrier of the company's advanced technology, technology standards run through all aspects of its technology innovation activities. High-tech companies in developed countries have adopted technology standards as an effective means to improve their competitiveness. The capability to set technology standards is a concrete reflection of technological research and development capabilities, and belongs to a type of technology standardization capabilities. Sun and others pointed out that, in a narrow sense, technology standardization ability is the ability to promote proprietary technology as an industry standard, and in a broad sense, it includes the ability to develop, patent, standardize and even industrialize [30]. Wang defines standardization ability as the carrier of the technology standard alliance, providing various advantageous resources for different stages of development of technology standardization, and successfully promoting the ability of technology standards to become market fact standards [31]. To summarize, technology standard-setting capability is the ability of an enterprise to develop and promote an advocated technological paradigm as the technology standard for the market.

(3) Technology innovation performance

In a narrow sense, Hagedoorn and Cloodt believe that the innovation performance of enterprises is measured by the introduction of research and development results into the market, which usually includes the market share of new products, new technology systems, or new equipment [32]. From a broad perspective, Ahuja and Lampert believe that corporate innovation performance is a series of processes from the creation of corporate innovation results to entering the market, and the benefits 
that companies gain in R\&D, technology, and innovation [33]. Technology innovation performance is a key aspect of enterprise innovation performance, and it is a comprehensive reflection of the enterprise technology innovation process and innovation results. Stock defines it as the performance created by output technologies in the process of technology innovation of enterprises, which is mainly reflected in newly developed products [34]. Based on a review of the above definitions, it can be seen that technology innovation performance is the efficiency and comprehensive benefits achieved by enterprises in technology innovation activities, including contributions to technology innovation capabilities and performance.

\subsubsection{Literature Review}

(1) Theoretical research on the relationship between enterprise collaboration R\&D network characteristics and technology innovation performance

The effects of an enterprise collaboration R\&D network on technology innovation performance depend on the network characteristics. Meagher et al. found that the potential for enterprise innovation originating from the technology spillover of internal R\&D or collaboration R\&D network partners, which have an important impact on technology innovation performance and technology spillover, depends on the enterprise collaboration R\&D network characteristics [35]. Many scholars showed that network centrality, connection breadth, and connection strength positively affected technology innovation performance [36,37]. Chiu verified that network capabilities and network center positions are positively related to innovation performance, and enterprises must focus on improving network capabilities, stay close to network center positions, and keep in touch with other companies to improve innovation performance [38]. Fang and Pigneur confirmed that the core enterprise innovation performance in a multinational collaboration R\&D network was positively affected by the network structure (network range and network density) and network relationship (connection strength, connection duration, standard distance, and network centrality) [39]. Phil, through empirical research on more than 1000 manufacturing companies, concluded that the heterogeneity of network resources provides enterprises with diversified resources, brings innovation heterogeneity, realizes more technology innovation elements, and promotes the improvement of corporate innovation advantages [40]. The network environment created by the enterprise collaboration R\&D network was beneficial for enterprises to obtain information, capital, manpower, knowledge, and other resources through connections, to reduce resource acquisition and integration costs, and to collaborate with other entities in developing new products. It also helped enterprises to continuously improve their technology innovation capabilities, to generate technology breakthroughs, to maximize economic benefits, and to improve technology innovation performance.

(2) Theoretical research on the relationship between enterprise collaboration R\&D network characteristics and technology standard-setting capability

An enterprise collaboration R\&D network is the embodiment of the collaborative innovation of multiple entities centered around enterprise. The technology standard is the driving force, the source of innovative ideas, and the inspiration for each innovation subject, and it is also the key to the success of cooperative innovation.

Lea and Hall pointed out that due to the limited capabilities of enterprises, it is difficult to formulate general technology standards alone; therefore, in order to initiate and establish technology standards, enterprises are keen to join the technology standards strategic alliance [41]. Lv proposed that technology research and development cooperation promotes the standardization of product elements [42]. For example, in the early 1980s, with the support of the European Union and the governments of member states, telecommunication operators and equipment manufacturers among member states formed a collaborative research and development network to successfully formulate common technology standards for GSM (Global System for Mobile Communications). Soh proposed that companies can establish their own technology as a standard, or join the competitor network to set 
a technology standard [43]. In the dominant design competition, companies establish a collaborative research and development network to attract complementary suppliers to improve their technology standard-setting capability and to promote the company's preferred technology standard as the mainstream technology standard. Wang believed that participating in the enterprise collaboration $R \& D$ network benefited the establishment of technology standard setting, and technology standard setting has shifted from a single enterprise to vertical and horizontal enterprises that form networks to participate in competition and collaboration [29]. Therefore, enterprises will actively participate in the collaborative research and development network and other entities in order to have an advantage in market competition and to enhance their ability to formulate their technology innovation results as the technology standard.

(3) Theoretical research on the relationship between technology standard-setting capability and technology innovation performance

Technology standard setting promotes the creation and adoption of standards and innovation [44]. Based on a survey, Li and Zhang believe that technology standard setting has a positive impact on technology innovation performance, which is conducive to saving raw materials, controlling costs and responding to market conditions in a timely manner, improving production efficiency, product quality, cost control and competitiveness, and improving product innovation benefits [45]. Zhou examined the relationships among R\&D strategy, technology standardization and technology innovation performance, and revealed the positive impact of standardization knowledge accumulation on technology innovation performance [46]. Leiponen proposed that the technology standard played an important role in performance and competitive advantage under the locking effect [47]. So, the stronger the enterprise's technology standard-setting capability, the stronger their ability to control the market. The legality of technology standards enables the sharing and support of resources and information flows, leading the direction of market development, and allowing the market to accept new technologies while taking market initiative and occupying more market share. Therefore, the standardization and guidance of technology standards can be used to accelerate technology innovation, improve new products or patent output, reduce innovation risks and R\&D costs, realize value creation, ensure new products' market prospects under industry standards, and improve technology innovation performance.

\subsubsection{Theoretical Model Construction}

Based on the above theoretical research and the social network analysis paradigm of "locationstructure-relationship", according to the indicators selected by Fang and Pigneur [39], the characteristics of enterprise collaboration R\&D networks are divided into network centrality, connection breadth, and connection strength. Network centrality represents the position of the enterprise in the network, which is used to measure the importance and superiority of the enterprise in the network. Connection breadth refers to the extent of different external knowledge, technology sources, or cooperation. A large number of channels reflects the diversity and openness of the network. Connection strength refers to the frequency of contact between the enterprise and the innovative partners in the network. It is a measurement of trust and intimacy. According to the research of Damanpour [48] and Zhang [49], technology innovation performance is divided into innovation efficiency and innovation benefits. Innovation efficiency is a reflection of the relationship between the resource input and the innovation output, such as the number of new products developed. More innovation output at a given resource input gives a higher innovation efficiency. On the other hand, innovation benefits relate only to the output. It is an index reflection of innovation effects and benefits such as the competitiveness, profit rate, and the number of patents issued to innovation products.

Therefore, network centrality, connection breadth, and connection strength can be used to represent the characteristics of an enterprise collaboration R\&D network. Innovation efficiency and innovation benefits are used to represent technology innovation performance. In order to investigate the mechanism of the enterprise collaboration R\&D network characteristics affecting 
technology innovation performance under the mediating role of technology standard-setting capability, the following theoretical model is constructed as shown in Figure 1.

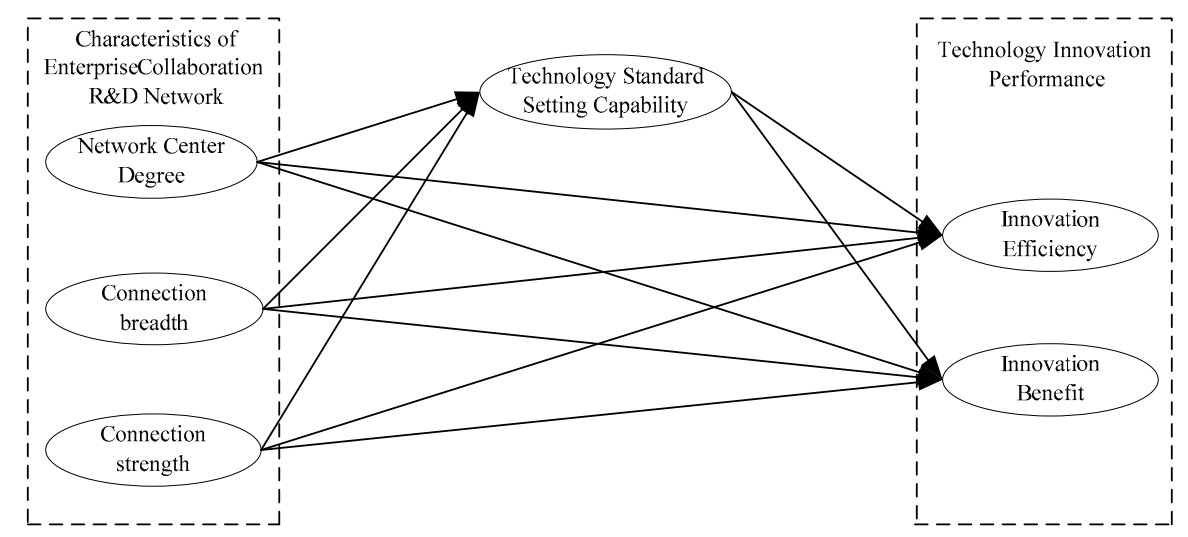

Figure 1. Theoretical model linking the characteristics of the enterprise collaboration R\&D network, technology standard-setting capability, and technology innovation performance.

\subsection{Formulation of Hypotheses}

\subsubsection{Enterprise Collaboration R\&D Network Characteristics and Technology Innovation Performance}

As shown in the previous section, the characteristics of the enterprise collaboration R\&D network and the innovation performance are represented by a few parameters. In order to investigate the relationship between the two in depth, hypotheses are set from different dimensions.

(1) The relationship between network centrality and innovation efficiency and innovation benefits

Powell pointed out that enterprises in the network center position have more resources and can control the flow of resources, which is conducive to multilevel technology cooperation and exchange, and has a positive impact on innovation efficiency [50]. Capaldo believes that centered companies in a collaboration R\&D network should effectively manage knowledge flow, innovation capabilities and network stability in the network to improve innovation performance [51]. In the collaboration $R \& D$ network, each entity is a message transmitter and filter. The more centrally located the enterprise, the more effective it is in obtaining more effective market information, controlling the information transmission path, broadening the information channels, and obtaining valuable knowledge and resources. In turn, the degree of profit acquisition is higher. Based on this, two hypotheses are set as follows:

Hypothesis 1: Network centrality has a positive impact on innovation efficiency.

Hypothesis 2: Network centrality has a positive impact on innovation benefits.

(2) The relationship between connection breadth and innovation efficiency and innovation benefits

Zhang empirically showed that enterprises in the collaborative R\&D network carry out research and development cooperation with various types of organizations, which is conducive for enterprises to acquire novel technologies and improve the complementary ability of process and technology [52]. Zhou et al. proposed that the wider the cross-organizational collaboration R\&D activities, the more beneficial it is for enterprises to increase the number of knowledge sources and thus improve their innovation performance [53]. With a higher degree of linkage, enterprises gain better heterogeneous technology and resource capabilities, and their opportunities to identify new innovations of value increase. This can provide them with more technological innovation elements, and promote product development and process links. The success rate of optimization and innovation of products can be 
increased, while the cost of new product development and production can be reduced. This can enhance the competitiveness of new products in the market, and hence enhance the innovation performance of enterprises. Based on this, the following two hypotheses are provided.

Hypothesis 3: Connection breadth has a positive impact on innovation efficiency.

Hypothesis 4: Connection breadth has a positive impact on innovation benefits.

(3) The relationship between connection strength and innovation efficiency and innovation benefits

Through empirical analysis, Chi pointed out that connection strength has a positive impact on the comprehensive index of technology innovation performance such as sales revenue, profit rate and new product quantity, and hence improves the efficiency of technology innovation [54]. Higher connection strength, higher trust and long-term cooperation vision between the subjects can reduce the threat of opportunistic behavior of information asymmetry, improve the overall operational efficiency of the network system, and stimulate the vitality and creativity of redundant resources within the technology innovation process. This helps enterprises to quickly identify market demand, improve the competitiveness of new product markets, and promote innovation efficiency and innovation benefits. Based on this, the following two hypotheses are provided.

Hypothesis 5: Connection strength has a positive impact on innovation efficiency.

Hypothesis 6: Connection strength has a positive impact on innovation benefits.

2.2.2. Enterprise Collaboration R\&D Network Characteristics and Technology Standard-Setting Capability

In this paper, the characteristics of enterprise collaboration R\&D networks are divided into network centrality, connection breadth, and connection strength. In order to further explore the relationship between enterprise collaboration R\&D network characteristics and technology standard-setting capability, the following dimensions are used to make hypothetical derivations.

(1) Relationship between network centrality and technology standard-setting capability

Zeng also proposed that the enterprise network location can positively influence the technology standard-setting capability $[55,56]$. Network centrality gives companies a better position to use multiple information sources to innovate strategic choices and enhance risk insights with a high degree of sensitivity to information and resources. At the same time, the company can use its high impact to spread internal technologies across the network. In conjunction with other entities in the network, it can achieve better investment efficiency and technology standard-setting capability. For example, the Global System for Mobile Communication standard has many participants, but companies in the center of the network dominate the development of technology standards. Based on this, the following hypothesis is set.

Hypothesis 7: Network centrality has a positive impact on technology standard development capabilities.

(2) The relationship between connection breadth and technology standard-setting capability

Zou and others believe that connection breadth provides diversified resources and technologies, and heterogeneous low-redundancy information is beneficial to the strategic layout of enterprises and can enhance technology standard-setting capability [37]. The flow and exchange of diversified information and resources under a high degree of linkage enhance the ability of enterprises to acquire heterogeneous resources and improve the diversification of enterprise technology. This can enable enterprises to integrate technologies in different fields and provide a compatibility framework. At the 
same time, it can utilize the value of technology combination. Companies in the network tend to obtain support from different entities within the network, and promote and develop general-purpose technology standards applicable to the entire industry. Based on this, the following hypothesis is set.

Hypothesis 8: Connection breadth has a positive impact on technology standard-setting capability.

(3) The relationship between connection strength and technology standard-setting capability

Delcamp proposed that the relationship between companies and other entities in the collaboration R\&D network increases the possibility of citation of patents in the development of technology standards [57]. When the network connection strength is high, the information exchange efficiency and accuracy are high, and opportunistic behavior is reduced. Common goals are pursued, and understanding and coordination can be improved. In order to pursue the dominant position of the industry and obtain monopoly profits, companies will deepen their close relationship with other entities in the network. Together, they can invest a substantial amount of time and resources to collaborate and innovate, promoting the output of innovation benefits, and hence achieve high-performance technology standards. Based on this, a hypothesis is set as follows.

Hypothesis 9: Connection strength has a positive impact on technology standard-setting capability.

\subsubsection{Technology Standard-Setting Capability and Technology Innovation Performance}

Wakke and other researchers investigated whether corporate intellectual property can be well protected through patents, and participation in formal technology standardization was found to be positively related to performance [58]. This demonstrates that technology standards, as a mature technology system, are beneficial to communications between enterprises. They also help enterprises in tracking the direction of technology development and maintaining a good link to consumer demand. Strong technology standard-setting capability is beneficial to the integration of technology standards and patents, to clarify product or service requirements and to successfully develop technology standards. By using the advanced nature of a technology standard, it can guide the development of strategic innovation plans, achieve technological breakthroughs, and accelerate the transformation of innovation results and innovation output. Technology standardization is the best way to transform innovation achievements into patented technology which can, in turn, be transformed into new products. The enhancement of technology standard-setting capability is beneficial to standardizing the production direction and process of the enterprise, which can enable high enterprise efficiency, improve enterprise profit and increase innovation benefits. Based on this, the following hypotheses are set.

Hypothesis 10: Technology standard-setting capability has a positive impact on innovation efficiency.

Hypothesis 11: Technology standard-setting capability has a positive impact on innovation benefits.

\subsubsection{Mediating Role of Technology Standard-Setting Capability}

Lee and Oh believe that innovation is the foundation and driving force for enterprises to participate in technology standard competition, so enterprises can participate in technology standard competition to generate patents, improve technology standards, and improve corporate performance [59]. Wang believes that the formulation of technology standards plays a vital role in technology cooperation innovation among different entities [31]. The key to innovation success is to transform innovation achievements into industrial technology standards to increase technological value, improve innovation efficiency, and create competitive advantage.

Under the competition of technology standards, improving technology standard-setting capability has been regarded as a strategic target of enterprises. Enterprises and other entities form a collaborative $R \& D$ network of enterprises, and, at the same time, strive to occupy the position of the network center. 
They will try to establish mutual benefit and win-win relationships with other entities through network connections while strengthening the diversity of the connections. The main entity is based on mutual trust, technology accumulation and integration of heterogeneous resources. Collaborative innovation in the research and development of technological achievements can result in patents, etc. General industry technology regulations are beneficial to the development of enterprises. Based on technology innovation achievements, enterprises and network entities always attempt to establish the industry's unified regulation under continuous negotiation, hence improving technology standard-setting capability. The setting of technology standards can accelerate $R \& D$, design, production and other aspects of new products, and hence improve the innovation output. At the same time, it provides a technology innovation platform for unique product specialization to enhance innovation efficiency and innovation benefits. Based on this, the following hypotheses are set.

Hypothesis 12: Technology standard-setting capability mediates between network centrality and innovation efficiency.

Hypothesis 13: Technology standard-setting capability mediates between network centrality and innovation benefits.

Hypothesis 14: Technology standard-setting capability mediates connection breadth and innovation efficiency.

Hypothesis 15: Technology standard-setting capability mediates between connection breadth and innovation benefits.

Hypothesis 16: Technology standard-setting capability mediates between connection strength and innovation efficiency.

Hypothesis 17: Technology standard-setting capability mediates between connection strength and innovation benefits.

\section{Empirical Research}

\subsection{Data Source}

A questionnaire was distributed nationwide in China, with more than $60 \%$ of the questionnaire respondents coming from Beijing, Shanghai, Guangdong, Jiangsu, Shandong, and Chongqing, and covering more than 12 industries including electronics and communications equipment manufacturing, biopharmaceuticals, materials, and new energy. Research and development management personnel who have knowledge of enterprise technology standardization and research and development, or employees with rich experience in technology research and development, were the research objects. Therefore, the object of the survey is extensive, which made it difficult to issue the questionnaire. In order to ensure the accuracy of the survey and improve the recovery rate of the questionnaire, some survey questionnaires were distributed through the Changchun Science and Technology Bureau channel and the network of human resources. For the others, we hired a professional data agency to issue them. We received a total of 350 responses to the questionnaires and conducted effective data screening one by one. We set question traps in the questionnaire so that the questionnaire is only valid if it is completed and logical, and a questionnaire fill time of less than $100 \mathrm{~s}$ was considered invalid. In the end, we surveyed a total of 256 valid questionnaires, accounting for $73 \%$ of the total questionnaires received. Among them, 129 valid questionnaires were collected through the channel and network resources channels of Changchun Science and Technology Bureau, and 127 valid questionnaires were collected through the questionnaire sample collection service channel.

\subsection{Measurement of Variables}

In the questionnaire, six variables were investigated, namely, the network centrality, the connection breadth, the connection strength, the technology standard-setting capability, the innovation efficiency and the innovation benefits. The network centrality table refers to scales designed by scholars such as Giuliani [60], and it covers four items including the company's reputation in the industry, the number 
of partners willing to collaborate with the company in innovative activities, etc. The connection breadth table refers to the scales of Eisingerich [61]. It includes the extent of links that exist between the company and innovative partners of different scales, technical levels and industry types. It also includes the ease for the company to establish innovation partnerships with local innovation partners. The connection strength refers to the scales of Zhang [62] and Pan [63], including four items such as the exchange frequency between the company and the innovation partners, and the amount of resources the company invested in cooperation with innovation partners. The technology standard-setting capability scale draws on the technology standardization capability index system constructed by Sun [30], covering four items including the research and development of a series of new technologies, and the products and technology standards the company has set for the service production process. The innovation efficiency and innovation benefits scale refers to the scale of Zhang [49]. It includes nine items such as the input and output rate of the company's new products, the value of the company's new product output as a percentage of total sales, etc. For each item, the 2017 data for the company surveyed were compared against the main competitors in the same industry in China.

\subsection{Reliability, Validity, and Related Analysis}

\subsubsection{Reliability Analysis}

The Cronbach's $\alpha$ coefficient was used in the data reliability analysis to reflect the internal consistency of the scale items. The $\alpha$ coefficient is between 0 and 1 . It is generally considered that an $\alpha$ coefficient above 0.7 indicates good data reliability. The higher the $\alpha$ coefficient, the higher the data reliability. The results of the data analysis performed using SPSS are shown in Table 1. It can be seen that the Cronbach's $\alpha$ coefficients of all variables are greater than 0.7 .

Table 1. Reliability analysis.

\begin{tabular}{ccc}
\hline Scale & Item & Cronbach's $\alpha$ \\
\hline \multirow{3}{*}{ Network Center Degree } & A1 & \\
& A2 & 0.861 \\
& A3 & \\
& A4 & \\
\hline \multirow{3}{*}{ Connection Breadth } & B1 & \\
& B2 & 0.779 \\
& B3 & \\
\hline \multirow{3}{*}{ Connection Strength } & C1 & \\
& C2 & 0.803 \\
& C3 & \\
Cechnology Standard-Setting & D1 & \\
Capability & D2 & 0.860 \\
& D3 & \\
& D4 & \\
& E1 & \\
Innovation Efficiency & E2 & 0.823 \\
& E3 & \\
& E4 & \\
& F1 & \\
& F2 & \multirow{2}{*}{ F3 } \\
Innovation Benefits & F4 & \\
& F5 & \\
\hline
\end{tabular}




\subsubsection{Validity Analysis}

AMOS was used for confirmatory factor analysis. Since each potential variable belongs to the first-order measurement model, an overall validity test was performed. The results of confirmatory factor analysis are shown in Figure 2 and Table 2. It can be seen that $\chi^{2} / \mathrm{df}$ is less than 2; $\mathrm{P}$ is greater than 0.05; GFI, AGFI, NFI, IFI, and CFI are higher than 0.9; and RMSEA and RMR are less than 0.05 . This shows that each fitting index is consistent with the standard and the factor structure is verified.

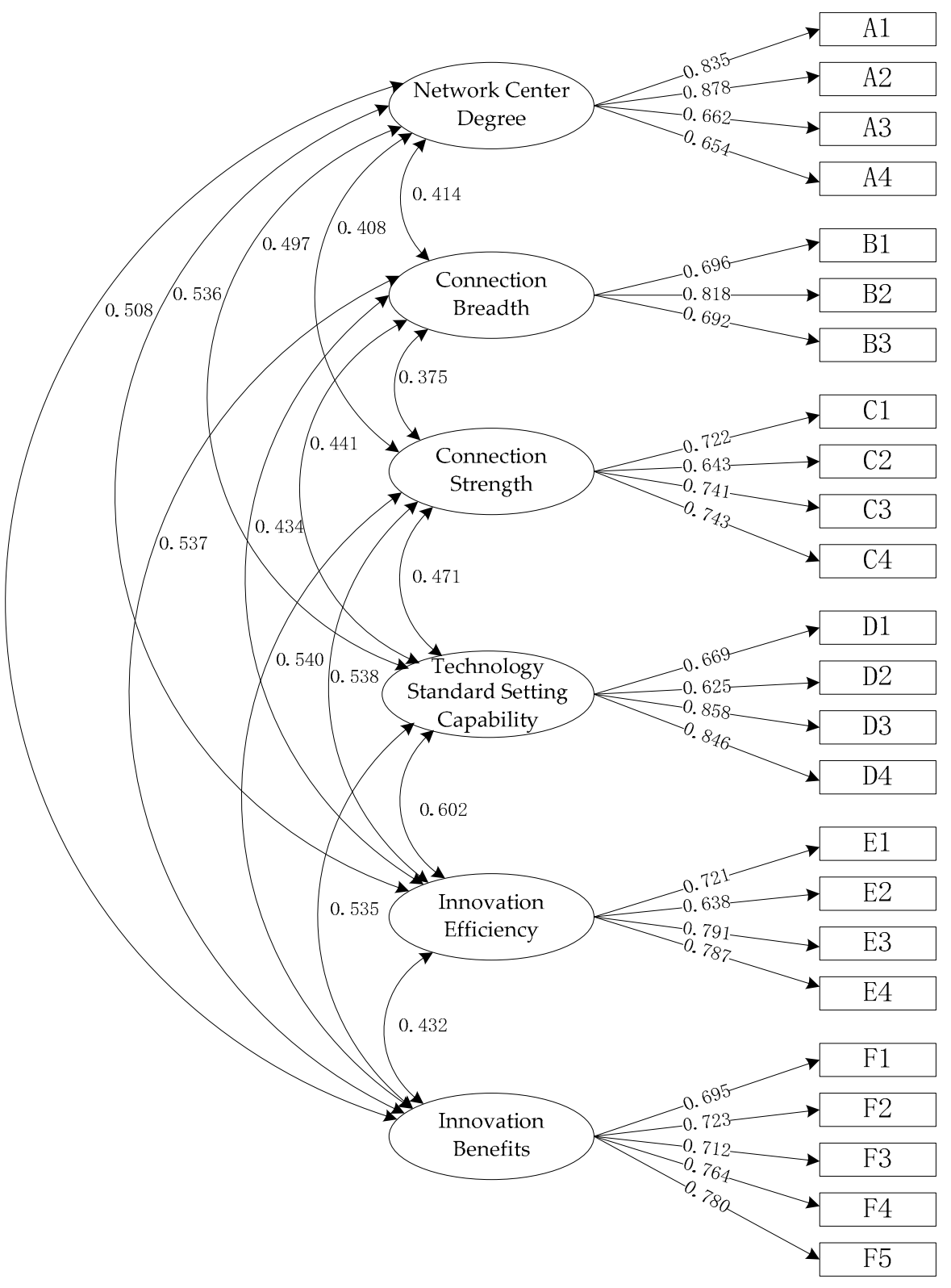

Figure 2. Confirmatory Factor Analysis.

Table 2. Fitting results of the overall measurement model on the confirmatory factor analysis.

\begin{tabular}{ccccccccc}
\hline $\mathbf{P}$ & $\chi^{2} / \mathbf{d f}$ & GFI & AGFI & NFI & IFI & CFI & RMSEA & RMR \\
\hline 0.062 & 1.146 & 0.923 & 0.902 & 0.915 & 0.988 & 0.988 & 0.024 & 0.042 \\
\hline
\end{tabular}

Based on the results of the confirmatory factor analysis, we evaluated the convergent validity of each potential variable by the values of factor loading, composite reliability $(\mathrm{CR})$, and average variance 
extracted (AVE). The results are shown in Table 3. The CR values of each dimension are greater than 0.7 , and the AVE values are greater than 0.5. The standardization factor load coefficient of all items on their corresponding latent variables are greater than 0.6 . The normalized estimates are all significant at $P<0.05$. As a result, the scale has good convergency.

Table 3. Convergence test results.

\begin{tabular}{|c|c|c|c|c|c|c|c|c|c|}
\hline & & & Estimate & S.E. & C.R. & $P$ & $\begin{array}{l}\text { Standardization } \\
\text { Factor Load } \\
\text { Coefficient }\end{array}$ & CR & AVE \\
\hline A1 & $<-$ & Network Center Degree & 1.000 & & & & 0.835 & \multirow{4}{*}{0.846} & \multirow{4}{*}{0.584} \\
\hline A2 & $<-$ & Network Center Degree & 1.059 & 0.070 & 15.084 & $* * *$ & 0.878 & & \\
\hline $\mathrm{A} 3$ & $<-$ & Network Center Degree & 0.836 & 0.077 & 10.888 & $* * *$ & 0.662 & & \\
\hline A4 & $<-$ & Network Center Degree & 0.830 & 0.076 & 10.918 & $* * *$ & 0.654 & & \\
\hline B1 & $<-$ & Connection Breadth & 1.000 & & & & 0.696 & \multirow{3}{*}{0.781} & \multirow{3}{*}{0.544} \\
\hline B2 & $<-$ & Connection Breadth & 1.167 & 0.119 & 9.793 & $* * *$ & 0.818 & & \\
\hline B3 & $<-$ & Connection Breadth & 1.034 & 0.112 & 9.233 & $* * *$ & 0.692 & & \\
\hline $\mathrm{C} 1$ & $<-$ & Connection Strength & 1.000 & & & & 0.722 & \multirow{4}{*}{0.805} & \multirow{4}{*}{0.509} \\
\hline $\mathrm{C} 2$ & $<-$ & Connection Strength & 0.925 & 0.102 & 9.032 & $* * *$ & 0.643 & & \\
\hline $\mathrm{C} 3$ & $<-$ & Connection Strength & 1.057 & 0.103 & 10.264 & $* * *$ & 0.741 & & \\
\hline $\mathrm{C} 4$ & $<-$ & Connection Strength & 1.068 & 0.104 & 10.232 & $* * *$ & 0.743 & & \\
\hline D1 & $<-$ & $\begin{array}{c}\text { Technology } \\
\text { Standard-Setting Capability }\end{array}$ & 1.000 & & & & 0.669 & \multirow{4}{*}{0.840} & \multirow{4}{*}{0.573} \\
\hline D2 & $<-$ & $\begin{array}{c}\text { Technology } \\
\text { Standard-Setting Capability }\end{array}$ & 0.990 & 0.079 & 12.586 & $* * *$ & 0.625 & & \\
\hline D3 & $<-$ & $\begin{array}{c}\text { Technology } \\
\text { Standard-Setting Capability }\end{array}$ & 1.352 & 0.122 & 11.093 & $* * *$ & 0.858 & & \\
\hline D4 & $<-$ & $\begin{array}{c}\text { Technology } \\
\text { Standard-Setting Capability }\end{array}$ & 1.295 & 0.116 & 11.201 & $* * *$ & 0.846 & & \\
\hline E1 & $<-$ & Innovation Efficiency & 1.000 & & & & 0.721 & \multirow{4}{*}{0.825} & \multirow{4}{*}{0.543} \\
\hline E2 & $<-$ & Innovation Efficiency & 0.974 & 0.104 & 9.325 & $* * *$ & 0.638 & & \\
\hline E3 & $<-$ & Innovation Efficiency & 1.209 & 0.109 & 11.095 & $* * *$ & 0.791 & & \\
\hline $\mathrm{E} 4$ & $<-$ & Innovation Efficiency & 1.137 & 0.100 & 11.390 & $* * *$ & 0.787 & & \\
\hline F1 & $<-$ & Innovation Benefits & 1.000 & & & & 0.695 & \multirow{5}{*}{0.855} & \multirow{5}{*}{0.541} \\
\hline $\mathrm{F} 2$ & $<-$ & Innovation Benefits & 1.070 & 0.104 & 10.272 & $* * *$ & 0.723 & & \\
\hline F3 & $<-$ & Innovation Benefits & 1.153 & 0.115 & 10.013 & $* * *$ & 0.712 & & \\
\hline $\mathrm{F} 4$ & $<-$ & Innovation Benefits & 1.194 & 0.113 & 10.537 & $* * *$ & 0.764 & & \\
\hline F5 & $<-$ & Innovation Benefits & 1.224 & 0.114 & 10.752 & $* * *$ & 0.780 & & \\
\hline
\end{tabular}

Note: ${ }^{*}$ stands for $P<0.05,{ }^{* *}$ stands for $P<0.01,{ }^{* * *}$ stands for $P<0.001$.

Next, we checked the discriminant validity of the variable scale. As shown in Table 4, the value on the diagonal is the square root of the AVE value. The square root of the AVE value of each variable is greater than the absolute value of the correlation coefficient of this variable with other variables. It is concluded that the discriminant validity between the variables is high.

Table 4. Discriminant validity check and correlation coefficient matrix.

\begin{tabular}{|c|c|c|c|c|c|c|}
\hline & $\begin{array}{c}\text { Network } \\
\text { Center Degree }\end{array}$ & $\begin{array}{l}\text { Connection } \\
\text { Breadth }\end{array}$ & $\begin{array}{l}\text { Connection } \\
\text { Strength }\end{array}$ & $\begin{array}{l}\text { Technology } \\
\text { Standard-Setting } \\
\text { Capability }\end{array}$ & $\begin{array}{l}\text { Innovation } \\
\text { Efficiency }\end{array}$ & $\begin{array}{c}\text { Innovation } \\
\text { Benefits }\end{array}$ \\
\hline Network Center Degree & $(0.764)$ & & & & & \\
\hline Connection Breadth & $0.414^{* * *}$ & $(0.738)$ & & & & \\
\hline Connection Strength & $0.408^{* * *}$ & $0.375^{* * *}$ & $(0.713)$ & & & \\
\hline $\begin{array}{c}\text { Technology } \\
\text { Standard-Setting Capability }\end{array}$ & $0.497^{* * *}$ & $0.441^{* * *}$ & $0.471^{* * *}$ & $(0.757)$ & & \\
\hline Innovation Benefits & $0.508^{* * *}$ & $0.537^{* * *}$ & $0.540 * * *$ & $0.535^{* * *}$ & $0.432^{* * *}$ & $(0.736)$ \\
\hline AVE & 0.584 & 0.544 & 0.509 & 0.573 & 0.543 & 0.541 \\
\hline
\end{tabular}

Note: * stands for $P<0.05,{ }^{* *}$ stands for $P<0.01,{ }^{* * *}$ stands for $P<0.001$. 


\subsubsection{Related Analysis}

The correlation analysis results are shown in Table 4. The network centrality, connection breadth, and connection strength have positive and significant correlation coefficients with the technology standard-setting capability, respectively. The network centrality, connection breadth, connection strength and technology standard-setting capability have positive and significant correlation coefficients with the innovation efficiency and innovation benefits.

\subsection{Hypothesis Testing and Results}

The correlation analysis conducted in the previous section can only measure the degree of association between variables in a preliminary manner. To further explain the relationship between independent and dependent variables, AMOS software was used to construct a structural equation model.

\subsubsection{X-Y Structural Equation Model Fitting Results and Path Analysis}

A structural equation model was constructed for the relationship between the corporate collaboration R\&D network characteristics and technology innovation performance. The resultant fitting indicators are shown in Table 5. P is greater than $0.05 ; \chi^{2} / \mathrm{df}$ is less than 2; GFI, AGFI, NFI, IFI, and CFI are higher than 0.9; RMSEA and RMR are less than 0.05. It can be seen that all fitting indices are in line with the standard, and the model fitting is satisfactory.

Table 5. X-Y model fitting results.

\begin{tabular}{cccccccccc}
\hline & $\mathbf{P}$ & $\mathbf{X}^{\mathbf{2}} / \mathbf{d f}$ & GFI & AGFI & NFI & IFI & CFI & RMSEA & RMR \\
\hline Fitting Results & 0.095 & 1.150 & 0.936 & 0.915 & 0.924 & 0.989 & 0.989 & 0.024 & 0.042 \\
\hline
\end{tabular}

The path analysis diagram is shown in Figure 3. From the results, it can be seen that, assuming Hypothesis 1 (H1) is correct, the network centrality has significant positive effects on the innovation efficiency (standardized path coefficient $0.329, P<0.05$ ). Assuming $\mathrm{H} 2$ is correct, the network centrality positively affects the innovation benefits (standardized path coefficient $0.248, P<0.05$ ). Assuming H3 is correct, the connection breadth has significant positive effects on the innovation efficiency (standardized path coefficient $0.167, P<0.05$ ). With $\mathrm{H} 4$ established, the connection breadth has significant positive effects on the innovation benefits (standardized path coefficient $0.313, P<0.05$ ). Assuming $\mathrm{H} 5$ is correct, the connection strength has significant positive effects on the innovation efficiency (standardized path coefficient $0.339, P<0.05$ ). Finally, with $\mathrm{H} 6$, the connection strength has significant positive effects on the innovation benefits (standardized path coefficient $0.320, P<0.05$ ).

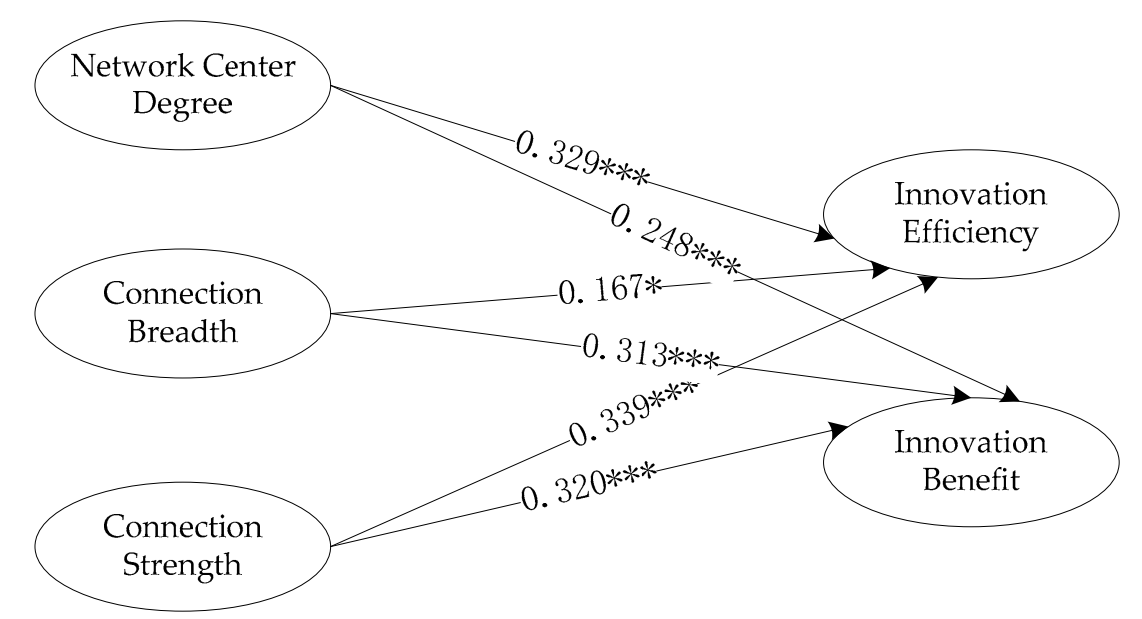

Figure 3. X-Y model path analysis diagram; Note: * stands for $P<0.05,{ }^{* *}$ stands for $P<0.01,{ }^{* * *}$ stands for $P<0.001$, stands for insignificant. 


\subsubsection{X-M-Y Structural Equation Model Fitting Results and Path Analysis}

A structural equation model was established to describe the correlation among the corporate collaboration R\&D network characteristics, technology standard-setting capability, and technology innovation performance. As shown in Table $6, P$ is greater than $0.05 ; \chi^{2} / \mathrm{df}$ is less than 2 ; GFI, AGFI, NFI, IFI, and CFI are higher than 0.9; RMSEA and RMR are less than 0.05. It is clear that all fitting indices are in line with the standard, and that the model fitting is satisfactory.

Table 6. X-M-Y model fitting results.

\begin{tabular}{cccccccccc}
\hline & $\mathbf{P}$ & $\chi^{2} / \mathbf{d f}$ & GFI & AGFI & NFI & IFI & CFI & RMSEA & RMR \\
\hline Fitting Results & 0.062 & 1.146 & 0.923 & 0.902 & 0.914 & 0.988 & 0.988 & 0.024 & 0.042 \\
\hline
\end{tabular}

The path analysis diagram is shown in Figure 4. The network centrality has a positive and significant impact on the technology standard-setting capability (standardized path coefficient 0.298 , $P<0.05)$, assuming H7 is correct. With H8 assumed, the connection breadth has a positive and significant impact on the technology standard-setting capability (standardized path coefficient 0.218 , $P<0.05)$. Assuming $\mathrm{H} 9$ is correct, the connection strength has a positive and significant impact on the technology standard-setting capability (standardized path coefficient $0.268, P<0.05$ ). The technology standard-setting capability has positive and significant impacts on innovation efficiency (standardized path coefficient $0.324, P<0.05$ ) and innovation benefits (standardized path coefficient $0.191, P<0.05$ ), assuming $\mathrm{H} 10$ and $\mathrm{H} 11$ are correct. At the same time, it can be seen that the connection breadth has no positive influence on the innovation efficiency in the $\mathrm{X}-\mathrm{M}-\mathrm{Y}$ structural equation model (standardized path coefficient $0.096, P>0.05$ ). However, the $X-Y$ structural equation model represents the overall effect of the connection breadth on the innovation efficiency, and the connection breadth of the total effect has a positive and significant impact on innovation efficiency. Therefore, the impact of the connection breadth on innovation efficiency is entirely through the indirect impact of intermediation, rather than direct impact.

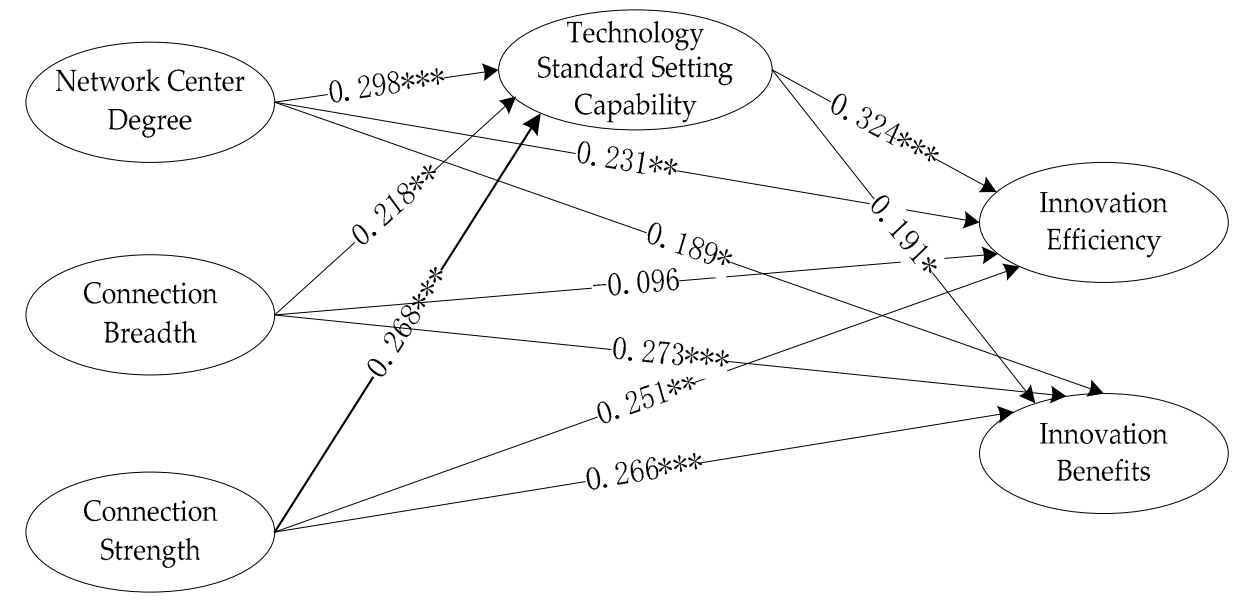

Figure 4. X-M-Y model path coefficient map; Note: * stands for $P<0.05,{ }^{* *}$ stands for $P<0.01$, ${ }^{* * *}$ stands for $P<0.001$, stands for insignificant.

\subsubsection{Mediating Effect Test}

Chen proposed that whether the simple mediating effect has a main observational mediating effect or not depends on whether the interval LLCI value to the ULCI value includes 0 : including 0 indicates no mediating effect, and not including 0 indicates a significant mediating effect [64]. After verifying that the mediating effect is significant, whether the medium is unique needs to be further explored. It is necessary to observe whether the interval LLCI value to the ULCI value includes 0 in 
the direct effect of the independent variable to the dependent variable. If it does not contain 0 , it is a partial intermediary, and if it does, it is a complete intermediary. The results of calculation using AMOS are shown in Table 7. The technology standard-setting capability plays a mediating role in the influence on network centrality, connection breadth, and connection strength on innovation efficiency and innovation benefits, assuming H12-H17 are correct. Among them, the technology standard-setting capability plays a full mediating role in the relationship between the connection breadth and the innovation efficiency, and for the rest, it has a partial mediating role.

Table 7. Mediating Effect Test Table.

\begin{tabular}{|c|c|c|c|c|}
\hline \multirow{2}{*}{ Path } & \multirow{2}{*}{$\begin{array}{l}\text { Standardization } \\
\text { Estimate Value }\end{array}$} & \multirow{2}{*}{$\begin{array}{l}\text { Standard } \\
\text { Error Value }\end{array}$} & \multicolumn{2}{|c|}{$\begin{array}{c}\text { Bootstrapping } \\
\text { (Bias-Corrected Percentile, 95\%) }\end{array}$} \\
\hline & & & LLCI & ULCI \\
\hline $\begin{array}{c}\text { Connection Breadth } \rightarrow \text { Technology Standard-Setting } \\
\text { Capability } \rightarrow \text { Innovation Efficiency (Mediating Role) } \\
\text { Connection Breadth } \rightarrow \text { Innovation Efficiency (Direct Effect) }\end{array}$ & $\begin{array}{l}0.071 \\
0.096\end{array}$ & $\begin{array}{l}0.033 \\
0.078\end{array}$ & $\begin{array}{c}0.014 \\
-0.057\end{array}$ & $\begin{array}{l}0.143 \\
0.251\end{array}$ \\
\hline $\begin{array}{c}\text { Connection Strength } \rightarrow \text { Technology Standard-Setting } \\
\text { Capability } \rightarrow \text { Innovation Efficiency (Mediating Role) } \\
\text { Connection Strength } \rightarrow \text { Innovation Efficiency (Direct Effect) }\end{array}$ & $\begin{array}{l}0.087 \\
0.251\end{array}$ & $\begin{array}{l}0.039 \\
0.084\end{array}$ & $\begin{array}{l}0.025 \\
0.085\end{array}$ & $\begin{array}{l}0.180 \\
0.417\end{array}$ \\
\hline $\begin{array}{c}\text { Network Center Degree } \rightarrow \text { Technology Standard-Setting } \\
\text { Capability } \rightarrow \text { Innovation Benefits (Mediating Role) } \\
\text { Network Center Degree } \rightarrow \text { Innovation Benefits (Direct Effect) }\end{array}$ & $\begin{array}{l}0.057 \\
0.189\end{array}$ & $\begin{array}{l}0.029 \\
0.077\end{array}$ & $\begin{array}{l}0.007 \\
0.038\end{array}$ & $\begin{array}{l}0.121 \\
0.337\end{array}$ \\
\hline $\begin{array}{c}\text { Connection Strength } \rightarrow \text { Technology Standard-Setting } \\
\text { Capability } \rightarrow \text { Innovation Benefits (Mediating Role) } \\
\text { Connection Strength } \rightarrow \text { Innovation Benefits (Direct effect) }\end{array}$ & $\begin{array}{l}0.051 \\
0.266\end{array}$ & $\begin{array}{l}0.028 \\
0.073\end{array}$ & $\begin{array}{l}0.006 \\
0.119\end{array}$ & $\begin{array}{l}0.116 \\
0.401\end{array}$ \\
\hline
\end{tabular}

\section{Conclusions and Implications}

\subsection{Research Conclusions}

The following conclusions can be drawn based on the theoretical analysis and empirical test. First, network centrality, connection breadth, and connection strength have positive and significant impacts on technology innovation performance. This is basically consistent with the conclusions of previous studies $[35,39,65]$, and further verifies the significant positive influence of network centrality, connection breadth, and connection strength on innovation efficiency and innovation benefits of technology innovation performance. We proved that the status of the network center possesses the accessibility, timeliness, and reference of the information. High connection breadth enables the enterprise to obtain heterogeneous resources, break through the constraints of internal resources, and inject new innovative elements into a weak link. High connection strength increases trust and credibility between enterprises. The close division of technological expertise makes R\&D activities more efficient. All of these factors are conducive for enterprises to collect and allocate network resources, promote the successful transformation of innovative resources, and produce breakthrough technology achievements. When the market demand changes, these aspects help in adjusting the innovation strategy in a timely manner, winning a sustainable innovative advantage, and improving the innovation efficiency and innovation benefits.

Second, network centrality, connection breadth, and connection strength have positive and significant impacts on technology standard-setting capability. There have been a few related studies in the past, and most of them relied on second-hand data to prove the positive relationship between the characteristics of the corporate collaboration R\&D network and the technology standard-setting capability $[37,55]$. In this paper, primary data were obtained through surveys to prove that network centrality enhances an enterprise's control over information resources and makes it the hub of 
information and resources. It also gives enterprises more rights in the process of standard setting. Connection breadth improves the level of technology diversity of enterprises, and enables enterprises to develop more technical combinations. It can help in promoting and developing universal technology standards for the whole industry. High connection strength increases credibility among subjects, increases the efficiency and accuracy of information exchange, and promotes technology research, development achievements, and patent output to create conditions for the successful formulation of technology standards.

Third, technology standard-setting capability has positive and significant impacts on innovation efficiency and innovation benefits. At present, there are few relevant empirical studies by scholars, most of which are about technology standardization, standard competition, and technology innovation performance, and their conclusions are inconsistent $[22,66]$. Through the investigation of data from Chinese high-tech enterprises, we conclude in this paper that high-technology standard-setting capability makes it easy for enterprises to use the normative guidance of technology standards to guide the production direction and order, which reduces repetitive R\&D activities. Utilizing the legality of the technology standard promotes exchanges among enterprises to share compatible technologies and encourages them to develop strategic innovation plans and accelerate the output of new products. It can help enterprises to lead the direction of industrial development and seize market opportunities, thereby enhancing innovation efficiency and innovation benefits.

And through the empirical investigation of high-tech enterprises in China, this paper verifies that the technology standard-setting capability plays a complete intermediary role in the relationship between connection breadth and innovation efficiency, while other variables play partial intermediary roles. However, the previous research on technology standard-setting was mostly qualitative or based on secondary data. So through validation, we believe that enterprises strive to occupy the position of the network center and strengthen their connection with the main entity in the network based on credibility. They also tend to integrate technology accumulation and heterogeneous resources in the network with diversified entities, and collaboratively innovate research and development to bring products to the market. Stakeholders will continue their negotiation in order to establish unified industry rules, which is conducive to the legalization of technical experience and the formulation of technology standards. The formulation of a technology standard provides technical specifications and guidance for R\&D, facilitates designing and production undertaken by enterprises, and provides a unique innovation platform for product specialization and price optimization. This increases innovation efficiency and provides innovative benefits.

\subsection{Research Implications}

From the perspective of practical application, China pays major attention to issues of technology standards. However, as the main body of technology standards, enterprises have lower awareness of participating in collaboration R\&D networks and establishing cooperative relationships with other entities in the network. Therefore, this paper focuses on technology standard-setting capability for enterprises to promote technology innovation performance, and thus promotes the development of enterprise innovation and the formation of competitive advantages that could have guiding significance. These can be reflected in the following three aspects:

(1) Sufficient exploitation of the value of the enterprise collaboration R\&D network

When there is fierce market competition, it is risky for a company to conduct research and development independently. It is also difficult for a single company to meet the technology needs of the market alone. Instead, enterprises should build a collaboration R\&D network, and expand their relationships with customers, suppliers, and industry associations. They should actively occupy a dominant position in the collaborative network, maintain control over information, resources and other entities, and seek a competitive advantage to attract partners. They should also conduct strategic planning and thinking from the perspective of the whole network. At the same time, they can focus on 
the diversity of contacts, access heterogeneous resources, and form a resource sharing mechanism. Timely adjustment of the strategic direction and meeting the diversified needs of innovative partners while creating new opportunities and values are also important. They should also focus on the closeness of communication, enhanced credibility, and continuous development through the necessary financial support and technical means, and also focus on improving network cooperation.

(2) Improvement of technology standard-setting capability

A technology standard represents the direction of technological evolution, and the formulation of technology standards can somewhat reduce the risks and uncertainties of technological development. In the process of production and operation, enterprises should transform their technology standard mindsets and improve their technology standard-setting capability. Increasing the investment in research and development leads to the formation of core patents while learning the advanced patent technology of network partners. While paying attention to the protection of independent intellectual property rights, enterprises should fully utilize the authority and guidance role of technology standards. At the same time, they should actively participate in the formulation of technology standards, take ownership, and promote technology patent utilization, patent standardization, and standard marketization.

(3) The importance of improving enterprises' technology innovation performance

Enterprises are the main subjects of innovation. Improving technology innovation performance enables enterprises to have an advantage in the market. Enterprises should actively establish and develop enterprise collaboration $R \& D$ networks with other entities, introduce technical talents, and enhance their independent innovation capability and the technical value of new products. These efforts will help them to win more market share and improve the core competitiveness of enterprises. Meanwhile, enterprises should also strengthen the protection of intellectual property rights, improve their technology standard-setting capability, and fully utilize the superiority and applicability of technology standards to improve business operations. Enterprises should include establishing corporate collaboration R\&D network platforms and enhancing technology standard-setting capability into their enterprise development priorities, producing an innovation strategy that aims to maximize corporate profits and innovation performance.

\subsection{Future Work}

To further expand the work presented in this paper, the following can be explored in future works. It will be important to obtain a random sample selected by a complete stratified quota on a national scale to expand the distribution range and quantity of samples. Second-hand data can also be introduced. Combining the questionnaire survey with panel data to analyze the relations among the variables is suggested. Control variables, such as industrial attributes, enterprise property, and firm size, can be added to control the effects of other factors on the relations among variables and reduce the limitations of research results. It will also be useful to select a typical enterprise for a case study and explore deeper relationships among variables through the capture of vertical data to make the research results more reliable.

Author Contributions: Writing: H.J. and S.G.; Provided the case and idea: H.J.; Collected data and estimated the empirical model: S.G. and Y.S.; Provided revised advice: K.S. and G.A.J.A.

Funding: This research was partially funded by the National Natural Science Foundation of China (NSFC) under Grant No. 71774067.

Conflicts of Interest: No potential conflict of interest was reported by the authors. 


\section{References}

1. Freeman, C. Networks of innovators: A synthesis of research issues. Res. Policy 1991, 20, 499-514. [CrossRef]

2. Weiss, M.; Cargill, C. Consortia in the standards development process. J. Assoc. Inf. Sci. Technol. 1992, 43, 559-565. [CrossRef]

3. Katz, M.L.; Shapiro, C. Network externality, competition and compatibility. Am. Econ. Rev. 1985, 75, 424-440.

4. Katz, M.L.; Shapiro, C. Technology adoption in the presence of network externalities. J. Political Econ. 1986, 94, 822-841. [CrossRef]

5. Farrell, J.; Saloner, G. Standardization, compatibility and innovation. Rand J. Econ. 1985, 16, 70-83. [CrossRef]

6. Farrell, J.; Saloner, G. Installed base and compatibility: Innovation, product preannouncements, and predation. Am. Econ. Rev. 1986, 76, 940-955.

7. Blind, K.; Thumm, N. Interrelation between patenting and standardisation strategies: Empirical evidence and policy implications. Res. Policy 2004, 33, 1583-1598. [CrossRef]

8. Eisenmann, T.; Parker, G.; Alstynemw, V. Strategies for two-sided markets. Harv. Bus. Rev. 2006, 84, 92-101.

9. Chakravarti, A.; Xie, J. The impact of standards competition on consumers: Effectiveness of product information and advertising formats. J. Mark. Res. 2006, 43, 224-236. [CrossRef]

10. Blind, K.; Mangelsdorf, A. Alliance formation of SMEs: Empirical evidence from standardization committees. IEEE Trans. Eng. Manag. 2013, 60, 148-156. [CrossRef]

11. Fang, F.; Dickson, K.; Wang, D. The standardization model of innovation: Case of high-technology enterprises. Chin. Manag. Stud. 2016, 10, 102-118. [CrossRef]

12. De Vries, H.J.; Verhagen, W.P. Impact of changes in regulatory performance standards on Innovation: A case of energy performance standards for newly-built houses. Technovation 2016, 48-49, 56-68. [CrossRef]

13. Wellman, B.; Berkowitz, S.D. Social structures: A network approach. Am. Political Sci. Assoc. 1988, 83, 1404.

14. Wasserman, S.; Faust, K. Social network analysis in the social and behavioral sciences. Soc. Netw. Anal. 2012, $45,3-27$.

15. Manupati, V.K.; Putnik, G.; Tiwari, M.K. Resources Calability in Networked Manufacturing System: Social Network Analysis Social Network Analysis Based Approach; Springer Publishing Company Press: London, UK, 2015.

16. Kilduff, M.; Brass, D.J. Organizational social network research: Core ideas and key debates. Acad. Manag. Ann. 2010, 4, 317-357. [CrossRef]

17. Yao, X.T.; Xi, Y.M. Social network theory and its application in enterprise research. J. Xi'an Jiaotong Univ. Soc. Sci. 2003, 3, 27-32.

18. Michalski, R.; Palus, S.; Kazienko, P. Matching organizational structure and social network extracted from email communication. In Proceedings of the International Conference on Business Information Systems, Berlin, Germany, 15 June 2011; pp. 197-206.

19. Xu, F.; Xu, L.M. A review of strategic alliance theory. Bus. Rev. 2003, 6, 14-20, 24, 65.

20. Marlena, L.M.; Santos, J.P.; Christian, A.; Llerena, G. Strategic alliances in higher education in Ecuador: The challenge of knowledge transfer and its effect on the learning curve. Suma De Negocios 2014, 5, 96-104.

21. Yang, R.; Huang, G.A. Network location and Innovation-Social network analysis of Hangzhou mobile phone industry cluster. J. Ind. Technol. Econ. 2005, 7, 114-118.

22. Lin, H.M.; Huang, H.C.; Lin, C.P. How to manage strategic alliances in OEM-based industrial clusters: Network embeddedness and formal governance mechanisms. Ind. Mark. Manag. 2012, 41, 449-459. [CrossRef]

23. Zeng, C.H.; Lin, D.M. The theoretical explanation of establishing strategic alliance for enterprises. Sci. Res. Manag. 2004, 25, 93-97.

24. Koza, M.P.; Lewin, A.Y. The co-evolution of strategic alliances. Organ. Sci. 1998, 9, 255-264. [CrossRef]

25. Grant, R.M.; Baden, F.C. A knowledge accessing theory of strategic alliances. J. Manag. Stud. 2004, 41, 61-84. [CrossRef]

26. Muthusamy, S.K. Learning and knowledge transfer in strategic alliances: A social exchange view. Organ. Stud. 2005, 26, 415-441. [CrossRef]

27. Sternberg, R.; Arndt, O. The firm or the region: What determines the innovation behavior of European firms. Econ. Geogr. 2001, 77, 364-382. [CrossRef]

28. Doloreux, D.; Shearmur, R. Collaboration, information and the geography of innovation in knowledge intensive business services. J. Econ. Geogr. 2012, 12, 79-105. [CrossRef] 
29. Wang, F.H. Research on multinational innovation networking strategy system based on technology standard. Sci. Technol. Policy 2008, 3, 65-68.

30. Sun, Y.W.; Hu, L.H.; Hu, Z.Y. Technological standardization ability chain: A new dimension of study for high-tech industry's technological capability. Financial Theory Pract. 2007, 6, 95-99.

31. Wang, D.P.; Wei, X.Y.; Zou, S.M.; Fang, F. Standardization capability of leading enterprises in technology standard alliance. Forum Sci. Technol. China 2017, 2, 92-97.

32. Hagedoorn, J.; Cloodt, M. Measuring innovative performance: Is there an advantage in using multiple indicators. Res. Policy 2003, 32, 1365-1379. [CrossRef]

33. Ahuja, G.; Lampert, C.M. Entrepreneurship in the large corporation: A longitudinal study of how established firms create breakthrough inventions. Strateg. Manag. J. 2001, 22, 521-543. [CrossRef]

34. Stock, G.N.; Greis, N.P.; Fischer, W.A. Firm size and dynamic technological innovation. Technovation 2002, 22, 537-549. [CrossRef]

35. Meagher, K.; Rogers, M. Network density and R \& D spillovers. J. Econ. Behav. Organ. 2004, 53, 237-260.

36. Chen, L.Y.; Xie, F.; Zeng, D.M. The effect of technological diversity of collaboration R \& D network and organizational slack on ambidextrous innovation-Based on the panel data of automobile enterprises in China. Soft Sci. 2015, 9, 9-13.

37. Zou, S.M.; Zeng, D.M.; Zhang, L.F.; Chen, W.J. Network relationship, technology diversification and technology standardization ability of enterprises. Sci. Res. Manag. 2017, 38, 12-20.

38. Chiu, T.H. How network competence and network location influenc innovation performance. J. Bus. Ind. Mark. 2008, 24, 46-55. [CrossRef]

39. Fang, G.; Pigneur, Y. The integrative model of international innovation network and performance. In Proceedings of the 3rd International Symposium on Global Manufacturing and China, Hangzhou, China, 8 September 2007; pp. 167-174.

40. Phil, H. Regional innovation potential: The case of the US machine tool industry. Work Stud. 2000, 49, 451-453.

41. Lea, G.; Hall, P. Standards and intellectual property rights: An economic and legal perspective. Inf. Econ. Policy 2004, 16, 67-89. [CrossRef]

42. Lv, T. Research On technology standardization and industry standard strategy. China Ind. Econ. 2005, 7, 43-49.

43. Soh, P.H. Network patterns and competitive advantage before the emergence of a dominant design. Strateg. Manag. J. 2010, 31, 438-461. [CrossRef]

44. Xie, Z.; Hall, J.; Mccarthy, I.P.; Shen, L. Standardization efforts: The relationship between knowledge dimensions, search processes and innovation outcomes. Technovation 2016, 48, 69-78. [CrossRef]

45. Li, Y.Q.; Zhang, X.J. Review on the Impact of Standardization on Technology Innovation and Performance of Companies. Soft Sci. 2009, 23, 61-64, 70.

46. Zhou, X.; Shan, M.; Li, J. R \& D strategy and innovation performance: The role of standardization. Technol. Anal. Strateg. Manag. 2017, 30, 778-792.

47. Leiponen, A.E. Competing through cooperation: The organization of standard setting in wireless telecommunications. Manag. Sci. 2008, 54, 1904-1919. [CrossRef]

48. Damanpour, F.; Wallker, M.; Avellaneda, C.N. Combinative effects of innovation types and organizational performance: A longitudinal study of service organizations. J. Manag. Stud. 2009, 46, 650-675. [CrossRef]

49. Zhang, F.H. Firm's social capital and S \& T innovation performance: Concept model and empirical analysis. $R$ E D Manag. 2006, 18, 47-53.

50. Powell, W.W.; Koput, K.W.; Smith-Doerr, L. Interorganizational collaboration and the locus of innovation: Networks of learning in biotechnology. Adm. Sci. Q. 1996, 41, 116-145. [CrossRef]

51. Capaldo, A. Network structure and innovation: The leveraging of a dual network as a distinctive relational capability. Strateg. Manag. J. 2007, 28, 585-608. [CrossRef]

52. Zhang, Y.; Wei, J. Diversity of R \& D partners and innovation performance: The moderating effect of R \& D cooperation experience. Sci. Sci. Manag. S. T. 2015, 36, 103-111.

53. Zhou, C.H.; Cao, Y.H. The organizational learning space: The creative effect of the closeness, the knowledge and the innovative unit. Manag. World 2011, 4, 84-97.

54. Chi, R.Y.; Tang, G.N. Research on the efficiency of regional technology innovation based on input and performance evaluation. Sci. Res. Manag. 2004, 25, 23-27. 
55. Zeng, D.M.; Dai, H.W.; Zhang, Y.Z. Research on the influence of enterprises on standardization based on network structure and resource endowment. Chin. J. Manag. 2016, 13, 59-66.

56. Zeng, D.M.; Yang, Q.; Dai, H.W. Collaborative R \& D network model and technological innovation efficiency: A case study of listed companies in the automotive industry. Forum Sci. Technol. China 2014, 10, $22-27$.

57. Delcamp, H.; Leiponen, A. Innovating standards through Informal consortia: The case of wireless telecommunications. Int. J. Ind. Organ. 2014, 36, 36-47. [CrossRef]

58. Wakke, P.; Blind, K.; Ramel, F. The impact of participation within formal standardizati-on on firm performance. J. Prod. Anal. 2016, 45, 317-330. [CrossRef]

59. Lee, H.; Oh, S. A standards war waged by a developing country: Understanding international standard setting from the actor-network perspective. J. Strateg. Inf. Syst. 2006, 15, 177-195. [CrossRef]

60. Giuliani, E.; Bell, M. The micro-determinants of meso-level learning and innovation: Evidence from a Chilean wine cluster. Res. Policy 2005, 34, 47-68. [CrossRef]

61. Eisingerich, B.; Bell, J.; Tracey, P. How can clusters sustain performance? The role of network strength, network openness, and environmental uncertainty. Res. Policy 2010, 39, 239-253. [CrossRef]

62. Zhang, H.Q.; Shang, T.T.; Shao, Y.F. The impact of embedded relationship on knowledge internalization in innovation network and choice of competition mode. Chin. J. Manag. 2016, 13, 605-612.

63. Pan, S.T.; Cai, N. Dimension exploitation and measurement of tie strength in enterprise network. China Soft Sci. 2010, 5, 108-115.

64. Chen, R.; Zheng, Y.H.; Liu, W.J. Mediation analysis: Principles, procedures, bootstrap method and applications. J. Mark. Sci. 2013, 9, 120-135.

65. Chen, S.Z.; Ye, J.F.; Lin, M. Network location difference, industry environment and network location transition of alliance enterprises. J. Manag. Sci. 2018, 176, 100-108.

66. Liu, Z.G. Technological Innovation, Technological Standards and Economic Development; Standards Press: Beijing, China, 2005.

(C) 2019 by the authors. Licensee MDPI, Basel, Switzerland. This article is an open access article distributed under the terms and conditions of the Creative Commons Attribution (CC BY) license (http://creativecommons.org/licenses/by/4.0/). 